\title{
FRONTERAS: DE LA COMUNIDAD A LA NACIÓN EN LA CASTILLA BAJOMEDIEVAL
}

\author{
TEÓFILO F. RUIZ \\ University of California \\ at Los Ángeles (USA)
}

\begin{abstract}
SUMARIO
1. La construcción de un espacio territorial y mental.- 2. Fronteras y soberanía a finales del Medioevo.- 3. Propiedad y límites a nivel local.- 4. Límites, consolidación de propiedad y derecho de "paso de tierra".- 5. La consolidación de la propiedad.- 6 . Derechos de entrada y salida.- Conclusión.
\end{abstract}

En la relación de los viajes de León de Rosmithal por España y Portugal durante los años de 1465 al 1467 se encuentran varios pasajes que describen cuando la comitiva, que acompañaba al noble Rosmithal, cruzaba de una región a otra o de un país a otro en la península. Estos pasajes del diario de viaje se marcan por su "liminalidad" (liminality)", una "liminalidad" enfatizada en la descripción del cruce de un río, en los encuentros, casi siempre negativos, con las demandas de una aduana o puerto fiscal, con la presencia de un castillo, que celosamente vigilaba una frontera territorial, y que indicaban la transición de una jurisdicción territorial a otra. Uno de estos

\footnotetext{
'El concepto de liminality tiene su origen en la obra de Arnold Van GENNEP (Les rites du passage. 1908) y más recientemente en la obra de Victor TURNER (The Ritual Process: Structure and Anti Structure. 1969) y se aplica más bien a ritos, con su marcada diferencia en tres partes: séparation, marge y agrégation. Parte de mi argumento es que la definición de una frontera, ya sea local o nacional es parte de un código simbólico y ritual.

"Anuario de Estudios Medievales". 27 (1997)
} 
momentos ocurre cuando Rosmithal y su grupo salen de tierras vascas para entrar en España (o sea en Castilla), y el autor nos advierte que "acaba la Vizcaya y empieza España"2. Cruzando el río Duero, "la frontera entre Portugal y Castilla," la narrativa del viaje describe un castillo en la ribera portuguesa desde donde su guarnición vigilaba el movimiento de los que intentaban entrar en el territorio de Portugal ${ }^{3}$.

Las relaciones de viajes de finales de la Edad Media y comienzos de la moderna incluyen numerosas menciones de estos momentos de transición de un territorio a otro, o el encuentro con barreras fiscales artificiales (una aduana, un castillo, un puerto fiscal), con límites geográficos (un río, una montaña) o con mojones, como era el caso en la raya entre Aragón y Castilla $^{4}$ que servían de punto concreto para definir la extensión de un territorio y para delimitar los territorios adyacentes. Aunque la jurisdicción política - o sea, el gobierno de un rey sobre un territorio, sobre una tierra particular- estaba siempre implícito en estas descripciones, el énfasis recae, una y otra vez, sobre las transiciones que ocurren en el ámbito o espacio territorial y en los accidentes geográficos y materiales que marcaban el paso de un país o comarca a otro. En el caso específico de Rosmithal, que Castilla (como espacio físico) terminaba aquí, en este punto determinado, y que Portugal, otro país, comenzaba también allí.

\section{LA CONSTRUCCIÓN DE UN ESPACIO TERRITORIAL Y MENTAL}

En una edición monográfica dedicada al siglo XIII parece un poco atrevido el comenzar con la evocación de una narración de viajes de finales del siglo XV. Sin embargo, las relaciones de viaje de Rosmithal y de otros viajeros extranjeros en España y Portugal de esa misma época, consciente o inconscientemente, enfocan uno de los temas más importantes de la historiografía actual. Específicamente, me refiero a la génesis del concepto

'José García Mercadal, ed. Viajes de extranjeros por España y Portugal (3 vols., Madrid, 1952), I, p. 263. Véase también la descripción de Antonio de Lalaing, I, p. 445 et passim.

3Ibidem, I, p. 272.

${ }^{4}$ Véase la relación de Enrique COOK en Viajes de extranjeros, I, pp. 1303-1304, del viaje de Felipe II a Zaragoza en 1585. El cronista explica con énfasis las diferencias de jurisdicción de un lado de la línea fronteriza al otro. 
de la nación y de un territorio definido en términos materiales y espaciales, que corresponde, en un sentido físico, a la formulación de una idea embrionaria de la soberanía. En la historiografía anglo-sajona, por citar sólo un ejemplo, el estudio de los borderlands, las tierras fronterizas - y por consiguiente lo que va implícito en estos estudios, el concepto de identidad territorial y nacional- es toda una industria de investigación.

En este artículo deseo explorar un aspecto específico en el desarrollo de la ideas de fronteras territoriales e intentar establecer una relación entre la génesis de conceptos de jurisdiccion territorial al nivel local en Castilla a finales del siglo XII y comienzos del XIII y la formación del estado moderno y de nuevos conceptos de soberanía a finales del siglo XV y comienzos del XVI. Uno puede afirmar que el concepto de fronteras territoriales entre dos jurisdicciones políticas está directamente relacionado con la formulación de la idea de la soberanía, y que una idea no existe o no puede ser formulada sin la otra. Una teoría de la soberanía no puede ser articulada, en principio, sin que el concepto mismo no se asiente en una percepción o en el imaginar del reino y, mucho más tarde la nación o estado político, como una entidad territorial con límites o fronteras fáciles de reconocer y de definir por escrito o en mapas. Esto es precisamente lo que Benedict Anderson describe en su importante libro, Imagined Communities, la transición de un reino dinástico, organizado alrededor de un centro (administrativo, social, etc.), al concepto del estado soberano, definido por un territorio demarcado legalmente 5 .

La idea de la soberanía en la Europa occidental medieval también surge de toda una compleja serie de circunstancias políticas, sociales e intelectuales que solamente podemos mencionar de paso en estas páginas y que no son, después de todo, el objeto de este estudio. Comenzando en el siglo XII, eruditos del derecho civil y canónico, así como filósofos y otros estudiosos enunciaron principios políticos que, ya para el siglo XVI, vinieron a ser identificados con el poder indivisible de los reyes o del pueblo'. Informado por los aspectos prácticos de la construcción de la nación desde el siglo XIII en adelante - aún aceptando el hecho de que este comienzo fue

\footnotetext{
${ }^{5}$ Benedict ANDERSON, Imagined Communities. Reflections on the Origin and Spread of Nationalism, edición revisada, Londres, 1991, pp. 19-22.

${ }^{6}$ Véase, por ejemplo, la obra de Jean Bodin, Method for the Easy Comprehension of History, trans. B, Reynolds, New York, 1969, $162 \mathrm{ff}$.
} 
solamente un embrión de lo por venir ${ }^{7}-\mathrm{y}$ sostenido por la recepción y reformulación del Digesto y otros códigos legales romanos, Agustino Triunfo, Marsilio de Padua, Bartolo de Monferrato y otros legistas y canonistas comenzaron a explorar nuevas formas de concebir el estado y los lazos que unían (y unen) a los que gobiernan con la tierra y con sus súbditos dentro del contexto del poder político. Aunque basadas en una tradición de la ley de origen romana, estas nuevas definiciones de lo que pudiesemos llamar una temprana soberanía (el término no se utiliza todavía en los siglos XIII y XIV) $-\mathrm{y}$ a pesar de su origen y praxis italiana- eran influenciadas por la consciencia de la territorialidad y de límites geográficos que emergen en esos siglos a un nivel, que podríamos llamar "nacional," en diversas regiones de occidente.

En muchos sentidos, podemos afirmar, una vez más, que estos conceptos iniciales de soberanía formulados en la Baja Edad Media se gestaban en formas de imaginar fronteras o límites territoriales, ya no solamente de crearlas como una categoría intelectual o del imaginario político, sino también como fronteras actualizadas en la realidad concreta de aduanas, puertos de peaje, castillos y otras pruebas materiales de "liminalidad" geográfica. En otras palabras, lo que intento describir en estas páginas es la evolución de la idea del reino desde una serie de conceptos tales como la comunidad de un pueblo, de, en este caso específico, cristianos, de los que comparten una lengua, o de los que están unidos al rey y al reino por lazos recíprocos de fidelidad, al sentido mucho mas amplio de una entidad política que incluye todos los elementos mencionados anteriormente dentro de un marco geográfico ya bien definido. Y el énfasis debe ser colocado en el "marco geográfico", o sea en la fisicalidad de la nación.

Después de tan larga introducción, es conveniente reiterar la idea o tesis de este artículo, o sea, que el desarrollo de la idea de la soberanía - en sus aspectos materiales así como ideológicos- en Castilla y en otras partes del occidente medieval, tiene su génesis, ya no sólo en las universidades y en las cortes, sino también en la comunidad local. Los hombres y mujeres del medioevo no pudieron comenzar a pensar en fronteras nacionales ni, por lo tanto, construir nuevos conceptos de soberanía, sin antes definir sus

\footnotetext{
${ }^{7}$ La mayor parte de los historiadores del medioevo ya insisten en el carácter preliminar de la formación del estado moderno en los siglos XIII y XIV. Véase Joseph R. STRAYER, On the Medieval Origins of the Modern State, Princeton, 1964; Ernst H. KANTOROWICZ, The King's Two Bodies, Princeton, 1957.
} 
propias comunidades locales, sus tierras y propiedades en términos de espacio material, sin haber antes pensado en los límites de sus tierras como señales concretas y específicas que definían hasta dónde llegaba su propiedad - colectiva o individual- y comenzaba la de otra persona o concejo municipal.

Lo que intento describir en estas páginas, por lo tanto, es el tránsito de la idea de límites de la comunidad local a la nación y los lazos que existieron y existen entre nuevas y más intensas preocupaciones por la propiedad y por límites territoriales al nivel local a finales del siglo XII y principios del XIII, y la formulación eventual del reino como la manifestación material de la soberanía a finales de la Edad Media y comienzos de la época moderna.

\section{Fronteras y SOBERANÍA A FINALES DEL MEDIOEVO}

El desarrollo de fronteras más o menos definidas politicamente y de fácil reconocimiento ocurrió en diferentes épocas en la Europa occidental y en muchos casos los límites territoriales no son completamente definidos hasta los años posteriores a la revolución francesa. En Francia, por citar un ejemplo, un sistema de aduanas que delimitaban el territorio del reino y que mantenían una cuidadosa vigilancia sobre las mercancías que entraban y salían, ya existía a finales del siglo $\mathrm{XIII}^{8}$. No es necesario explicar los beneficios fiscales de estos tipos de aduanas y puertos de peaje. Con el tiempo, se convirtieron en una importante fuente de ingresos para la monarquía y fueron, al mismo tiempo, una forma de articular el creciente centralismo de los reinos bajomedievales y de apoyar fiscalmente este proceso de centralización. Así mismo, aduanas y puertos fiscales eran un lugar ideal para entrenar a la incipiente burocracía real, fuente de trabajo para los favorecidos por el rey, y, en fin, emblemáticas del poder real. Éste fue, ciertamente, el caso en Castilla, donde los puertos fiscales marítimos en el mar Cantábrico, como Laredo, Castro Urdiales, San Vicente de la Barquera, San Sebastián, Fuenterrabía y otros, generaban grandes cantidades de ingresos procedentes de impuestos para la Corona castellana. Más aún,

\footnotetext{
${ }^{8}$ Véase Joseph R. STRAYER, Pierre de Chalons and the Origins of the French Customs Service. "Medieval Statecraft and the Perspectives of History: Essays by Joseph R. Strayer", eds. John F. Benton y Thomas N. Bisson, Princeton, 1971, pp. 232-238.
} 
una gran parte de los oficiales reales, cuyos nombres aparecen en las "Cuentas del Rey Don Sancho de 1293-94", como recaudadores de impuestos y tasas en los puertos del Cantábrico durante esa época, reaparecen en gran número más tarde con otras responsabilidades dentro de la burocracía real ${ }^{9}$.

En Castilla, los puertos fiscales no se limitaron a zonas marítimas o a puertos de montaña, que servían de fronteras fiscales entre las diferentes regiones del reino. Con el tiempo podemos ver cómo existe una gran preocupación política por extender estas barreras fiscales a las fronteras geográficas del reino. Enrique III (1390-1406) en un privilegio confirmado por su hijo, Juan II, en 1446 estableció aduanas para controlar el trafico comercial y tasar mercancías exportadas e importadas de los reinos de Aragón y Navarra. "Puertos secos" fueron establecidos en Vitoria, Calahorra, Logroño, Ágreda, Soria y Molina en 1435, cuando Juan II determinó que todas las mercancías que iban y venían de Aragón y Navarra debían de hacerlo a través de los susodichos puertos y pagar la tasa determinada por el rey ${ }^{10}$.

En un sustancioso artículo, María Asenjo ya ha mostrado como "los términos territorio y frontera definen una realidad espacial concreta", y cómo, a finales del siglo XV, este territorio de frontera fue demarcado por aduanas, agentes de la burocracia real y una constante presencia militar. Aunque en este período la frontera "es percibida de modo distinto por parte de los vecinos del entorno...ciertamente [también] delimitaba soberanías distintas a uno y otro lado..." Aún mas, como Asenjo y otros ya han mostrado, la fronteras tenían su propia realidad política e institucional, una realidad que demandaba defensa militar y vigilancia fiscal ${ }^{11}$.

En Castilla, estos aspectos de la construcción material de fronteras nacionales tenían su contrapartida en la formulación ideológica del concepto de patria como tierra, o sea, la integración en las obras de los cronistas catellanos y de los tratadistas políticos de la época del concepto de patria

"Véase T.F. Ruiz, Burgos y el comercio castellano en la Baja Edad Media. Economía y mentalidad, "The City and the Realm. Burgos and Castile, 1080-1492", Aldershot, 1992.

${ }^{10}$ En esta sección sigo fielmente la pauta establecida por el excelente trabajo de María ASENJO GONZÁLEZ, Actividad económica, aduanas y relaciones de poder en la frontera norte de Castilla en el reinado de los Reyes Católicos, "En la España Medieval", 19 (1996), pp. 275 309.

"Ibidem, pp. 275-276. 
- heredado de fuentes romanas- con la más amplia idea de la tierra. Como paralelo cronológico de estas construcciones ideológicas encontramos nuevas formas de imaginar la propiedad, o sea de imaginar la tierra y sus límites al nivel local a finales del siglo XII y principios del XIII.

En lo que se refiere a la formulación ideológica, Ariel Guiance en un artículo de próxima publicación muestra como, desde finales del siglo XII, las crónicas castellanas y otros tratados históricos comenzaron a identificar y a justificar la guerra contra los Moros como "la defensa de la tierra". En efecto, que en los siglos XII y XIII y, probablemente en los dos siglos que siguen, el concepto de patria no había sido articulado en su acepción moderna. Como Guiance afirma, "...esa noción de patria como parte de un concepto mayor, el de la tierra - que, según veremos, no es simple sinónimo-, comprobaremos que tal identificación no sólo es posible sino que se ajusta de manera mucho más cabal al espíritu hispano"'2.

\section{PROPIEDAD Y LÍMITES A NIVEL LOCAL}

Debemos dejar a un lado las definiciones ideológicas de conceptos de territorialidad y concentrarnos en el mundo rural, específicamente, a finales del siglo XII y principios del XIII cuando nuevas formas de concebir la propiedad en términos espaciales aparecen en el mundo castellano. Hay que reconocer que límites geográficos - locales o no- han sido siempre parte del paisaje mental del ser humano, y que lo que intento describir y explicar en estas páginas es una transformación cualitativa y cuantitativa en la forma en que la propiedad es definida e imaginada en esta época. La evidencia más importante a este respecto es la transformación que ocurre en estos siglos en la manera en que individuos de diferentes clases sociales intentaban retener la propiedad en el seno de sus familias a través de sus testamentos y otros instrumentos legales. En otros de mis trabajos ya he mostrado como las donaciones y testamentos experimentaron un cambio radical en su método de redacción y en su contenido alrededor del año 1200. Dinero en efectivo, que reemplaza a tierras como lo que es donado, o rentas - las últimas por lo general en unidades de cereales (pan) o vino- eran

\footnotetext{
${ }^{12}$ Ariel GuIANCE, Morir por la patria: La tierra o la fe en el pensamiento castellano medieval, de próxima aparición en versión inglesa en el "Journal of Medieval History".
} 
dados a monasterios e iglesias bajo condiciones muy restrictivas. Más aún, las cláusulas de donaciones o testamentos especificaban las mandas de tal forma que no permitían el uso de los fondos testamentarios o rentas de otra forma distinta a la que se especificaba en el documento. Ya en el siglo XIV, los ejecutores de los testamentos eran, por lo general, parientes del difunto(a), ejecutores seculares encargados de verificar que las disposiciones del testamento se cumplían. Al mismo tiempo, un buen número de las capellanías y otras mandas piadosas eran reservadas para los parientes del testador, asegurando así, la permanencia de la propiedad y sus beneficios dentro del seno de la familia ${ }^{13}$.

Las Siete Partidas, un código legal de la segunda mitad del siglo XIII, refleja, en una forma aún más explícita y detallada, la preocupación de la sociedad castellana por cuestiones de propiedad. La primera partida incluye una serie de títulos que negaban a las iglesias el derecho a la propiedad de los feligreses que muriesen sin testamento. La misma partida también enumeraba las razones por las cuales la propiedad de la iglesia podía ser enajenada: 1) por deuda; 2) para rescatar a feligreses que no se pudiesen costear su rescate de manos de los moros; 3) para alimentar a los pobres en tiempos de hambruna; 4) para construir o renovar las iglesias; 5) para ampliar los cementerios. Otros títulos de las partidas definían la propiedad eclesiástica, establecían penas severas contra aquellos culpables de enajenar el dominio real y creaba procedimientos elaborados para proteger la propiedad de los cristianos prisioneros de los moros ${ }^{14}$. Las partidas, otros códigos legales y las ordenanzas de las Cortes reflejan - como lo hacen los testamentos y donaciones de la época- un interés creciente en la preservación y mantenimiento de la propiedad individual. En otras palabras, una nueva forma de concebir la propiedad, sobre todo la propiedad territorial. Al mismo tiempo, la legislación de mediados del siglo XIII y los susodichos testamentos y donaciones nos muestran el abismo que comienza a abrirse entre dos diferentes conceptos, el uno secular y el otro religioso, de la propiedad y de como administrarla.

\footnotetext{
${ }^{13}$ Véase T.F. Ruiz, The Business of Salvation, de próxima publicación en una Colección de ensayos en honor de Joseph F. O'Callaghan; y también Propietat i llengua: Canvis de valors a la Castella medieval, "L’Avenç", 219 (abril 1997), pp. 63-67.

${ }^{14}$ Siete partidas, I, tít. XIII, ley 6; tít. XIV, ley 1; tít XXI, leyes 3, 4 \& 5; partida II, tít. XVII, leyes $1 \& 2$. En Los códigos españoles concordados y anotados (12 vols., Madrid, 1847 1851), II, pp. 224, 229-230, 296-298, 431-433.
} 


\section{LÍMITES, CONSOLIDACIÓN DE LA PROPIEDAD Y DERECHOS DE TRANSMISIÓN DE LA TIERRA}

Los testamentos y la legislación, sin embargo, sólo nos proporcionan un punto de vista de los cambios que tuvieron lugar en la percepción de la propiedad y en las nuevas actitudes hacia ella. Existe abundante información que nos da testimonio de una transformación en el sistema de valores y, por consiguiente, en la relación del individuo con la tierra, o sea, con la propiedad, hacia el año 1200.

\section{Limites}

En el sentido más simple, uno puede describir esta transformación como el tránsito de un concepto a otro; o sea, de la construcción ideológica de la propiedad como una forma de jurisdicción - una jurisdicción en la cual los lazos entre derechos legales, rentas y espacio físico no estan todavía completamente integrados - a una idea de la tierra que está asentada completamente en nociones de espacio geográfico y localizadas dentro de lo que pudiésemos describir como un mapa mental que concuerda con un espacio físico. Lo que intento describir en estas páginas, por lo tanto, es la evolución del concepto de jurisdicción señorial o la jurisdicción como derecho en áreas rurales a un concepto de posesión física -el sentido, en un aspecto material mas específico, de que esta es mi tierra (ya sea porque poseo el dominio de ella o porque tengo el usufructo a largo plazo), una tierra que puede ser medida y que se extiende dentro de unos límites determinados, que ya en los siglos XII y XIII son indicados de una manera específica.

Estas transformaciones ocurren a dos niveles: a) en el más amplio contexto del reino en todo el mundo occidental medieval, donde, como he indicado anteriormente, ya a finales del siglo XIII, aduanas y castillos establecían los límites geográficos del reino; y b) al nivel local. Como ya he indicado anteriormente, hay una relación entre estos dos fenómenos y, como la formación de un sistema local de límites territoriales es un ingrediente necesario y pre-condición para la génesis de fronteras territoriales al nivel nacional y de la idea de la nación en si misma.

En el período que va de finales del siglo XII a mediados del XIII, las fuentes castellanas nos proporcionan abundantes ejemplos de esta 
transición. A todo lo largo de la Castilla meridional, aldeas, monasterios y pequeños propietarios litigaban unos contra otros, con frecuencia tomaban las armas en acciones violentas y apelaban al rey con la misma frecuencia para que el monarca ordenase inquisiciones y arbitrajes que determinaran ya no sólo la jurisdicción de una aldea o monasterio sobre cierta propiedad sino también, y mucho mas importante para nuestro argumento, la real extensión territorial de la propiedad en debate.

Hay que admitir que en una época mucho más temprana, ya existía una preocupación por determinar la jurisdicción señorial así como la extensión territorial. En 1028, la reina Jimena, u oficiales reales en su nombre, determinaron la jurisdicción de Vallarta, especificando dónde radicaban los límites de la población: "en la fuente de Fonte vascones, en el valle de Covo en San Justo"15. Aún así, en la lectura más optimista de este documento, la definición de estos límites carecía de precisión y daba una visión imperfecta de la extensión material de la propiedad en cuestión. A finales del siglo XII y comienzos del XIII, sin embargo, aunque las peculiaridades naturales del terreno, o sea, ríos, una colina, un camino o "carrera", todavía determinaban algunos de los límites territoriales a nivel local (como también lo hacían a nivel del reino), las propiedades - la tierra- comenzó a ser marcada por señales artificiales (los mojones). En 1170 , el conflicto entre el concejo de Oña y el monasterio de Santa María de Nájera sobre los límites de Trespaderne y Castrillo llevó al nombramiento de un grupo de árbitros que procedieron a determinar quien poseía qué tierras específicas en la región. Aunque los accidentes geográficos guardan todavía su importancia cuando hay que determinar los límites de la propiedad, uno de los árbitros, Iohan Adcona, portarius regis, colocó mojones en todos los puntos críticos ${ }^{16}$

A principios del siglo XIII observamos una tendencia, cada vez más acelerada, a determinar con mayor claridad los límites de la propiedad. Esto es obvio en una serie de privilegios de Fernando III, en los cuales equipos de cuadrilleros regios recibieron órdenes de levantar mojones por todo lo largo y ancho de los límites de tierras municipales, eclesiásticas y señoriales y de establecer, de una vez para siempre, la extensión física real de las

\footnotetext{
${ }^{15}$ Cartulario de San Millán de la Cogolla (759-1076), ed. A. UBIETo ArTETA, Valencia, 1976, pp. 186-187.

${ }^{16}$ Documentación del monasterio de San Salvador de Oña (1032-1284), ed. I. OCEJA GonZALO, Burgos, 1983, pp. 53-54 ("Fuentes medievales castellano-leonesas", 3).
} 
propiedades en cuestión. En el conflicto entre los concejos de Madrid y Segovia sobre los límites reales de cada municipio en la región de Valdemoro, los agentes del rey erigieron 42 mojones, algunos en las cimas de colinas, otros cerca de los caminos y otros en los valles. El documento es bastante preciso en su descripción del lugar donde los mojones debían ser colocados: "Et XXXV mojón en somo de la Pedriza sobre Valde Ezebreros en las cabeças de Don Aparicio"17

Estos mojones o símbolos de espacios limítrofes, erigidos a lo largo de toda Castilla en el siglo XIII, articulan, en un sentido práctico y, al mismo tiempo, simbólico, la génesis de nuevos conceptos de propiedad. Los aldeanos, los pobres campesinos, furiosos contra estas nuevas formas de organizar el espacio rural, quitaban los mojones con frecuencia, lo que llevaba a todo un nuevo ciclo de litigios y arbitrajes. Estos conflictos nos dan también una idea de la ansiedad creada por estos cambios de mentalidad y de valores, y de la percepción espacial de la tierra. En los Milagros de Nuestra Señora (c. 1250) de Gonzalo de Berceo, el milagro XI nos relata la historia de un labrador avaro que "más amaba la tierra que no a su Creador, y de muchas maneras era revolvedor," y quién, para aumentar su heredad, movió ilegalmente los mojones que delimitaban sus tierras. Aunque al final, por su devoción a la Virgen, el alma del labrador es liberada del infierno, el poema denuncia la avaricia del labrador y nos revela todo un nuevo sistema de valores en proceso de gestación. Un mundo de límites bien delineados, indicado por señales artificiales, los mojones, reemplaza la ambigüedad y fluidez de una época anterior, cuando los límites de la propiedad eran determinados por los accidentes del paisaje $\mathrm{e}^{18}$.

Quizás uno puede afirmar que el siglo XIII no era muy diferente de los siglos que le precedieron en su interés por definir la extensión de la

\footnotetext{
${ }^{17}$ Julio GonZález, Reinado y diplomas de Fernando III (3 vols., Córdoba, 1980-1983), III pp. 183-187. Para otros ejemplos de la colocación de mojones, véase III, docs. 651, 673, 696, 784 et passim. También en Documentación de los archivos catedralicio y diocesano de Salamanca, ed. J.L. MarTín MarTín, Salamanca, 1977, doc. 192b (1236); Recueil des chartes de l'abbaye de Silos, ed. M. FEROTIN, Paris, 1897, p. 203; Fuentes para la historia de Castilla, ed. L. SERrano (3 vols., Valladolid, 1906-1910), I, pp. 144-145; II, pp. 107, 109. En el conflicto entre el monasterio de San Pedro de Gumiel de Izán y el concejo de la aldea de Gumiel, 17 hombres de diferentes villas actuaron como árbitros, colocando 20 mojones en los límites entre la aldea y las tierras del monasterio: Archivo Histórico Nacional, carp. 232, $\mathrm{n}^{\circ}$ $9(29-8-1255)$. Véase también AHN, carp. 380, $\mathrm{n}^{\prime \prime \prime} 16$ y 17 (1255); carp. 300, $\mathrm{n}^{\circ} 2$ (1287); carp. 225, no 3 (1290); carp. 239, $\mathrm{n}^{\circ} 17$ (1-9-1290); carp. 233, n⿳3 3 (6-6-1293), et passim.

${ }^{18}$ Gonzalo de BerCeO, Milagros de Nuestra Señora, Madrid, Castalia, 1982, pp. 59-60.
} 
propiedad y, que si la documentación existiese, en ella podríamos encontrar referencias a litigios sobre límites territoriales. El hecho es que existen muchos más documentos para comienzos del siglo XII en Castilla que para una época similar en los siglos XIII y XIV. Sin embargo, aunque la documentación incluye, de vez en cuando, litigios sobre límites o demarcación de tierras, la mayor parte de los documentos se concentran en transacciones de terrenos, donaciones y otras formas de transferencia de propiedad en las cuales las referencias a los límites de la tierra o son vagas o no existen. La otra objeción a mi argumento es que quizás no existió ningún cambio fundamental en la manera de imaginar la propiedad, sino que la respuesta se halla en el hecho de que existía mayor presión sobre la tierra $\mathrm{y}$, por lo tanto, un mayor interés por parte de individuos, concejos municipales, etc., en determinar los límites de la propiedad. Cualquiera que fuese la razón $-\mathrm{y}$ parece que a finales del siglo XII y principios del XIII había una creciente competencia por montes y pastos en algunas regiones del norte de Castilla, a pesar de la general pobreza demográfica del reino- un nuevo interés en las características físicas de la tierra es fácilmente discernible. Este interés es manifiesto en dos tipos de discursos que, aunque distintos, no eran necesariamente incompatibles uno con el otro.

Uno de estos discursos recalcaba la jurisdicción legal o señorío - lo que generalmente, pero no siempre correctamente, podríamos describir como lazos feudales - y su lenguaje de fórmulas y ritos sociales llegan a ser sinónimos con la tierra de señorío y con otros tipos de propiedad semejantes ${ }^{19}$. El otro discurso, sin abandonar por completo el casi ritualizado lenguaje del poder señorial, expresaba un interés mucho más acentuado en la realidad concreta de la tierra. No nos debe sorprender que el primero de estos discursos aparezca de forma preeminente en las transacciones de señores poderosos, ya sean seculares o eclesiásticos. Por lo tanto, en una época tan tardía como la mitad del siglo XIV, como nos muestra el gran Becerro de behetrías, la jurisdicción y derechos señoriales eran expresados en términos de rentas feudales. Por otro lado, las transacciones de tierras y los litigios de personas menos poderosas o sin el prestigio social de los señores mencionados en el Becerro, así como de comunidades rurales entre ellas mismos o contra sus señores nos revelan un intenso interés en definir

\footnotetext{
${ }^{19}$ Véase Carlos M. Reglero de LA Fuente, Los señoríos de los Montes de Torozos. De la repoblación al Becerro de Behetrías (siglos X-XIV), Valladolid, 1993, p. 30.
} 
la propiedad en términos de su espacio físico y de sus límites geográficos ${ }^{20}$ En muchos sentidos, la mayor presencia de pequeños campesinos y miembros de las oligarquías urbanas en la vida económica del reino - y por lo tanto en la documentación- contribuyó directamente a estos cambios en la mentalidad y en el sistema de valores de la sociedad castellana.

Podemos afirmar que este nuevo interés por los límites y por las nuevas formas de definir la propiedad forma parte de un discurso del poder que sirve de alternativa al discurso del poder señorial. Este nuevo discurso -o contra-discurso (counterdiscourse) para emplear los términos que utiliza Foucault, está basado en la tierra como algo físico y tangible y está articulado en un lenguaje que es también nuevo. Nuevo porque los conceptos en sí son nuevos, y nuevo porque la lengua misma era el castellano, una lengua que aparece con más frecuencia en la documentación de finales del siglo XII y principios del XIII en transacciones de propiedad. Por lo tanto, en testamentos, en documentos de arbitraje, este interés en la propiedad y en el aspecto físico de la tierra, el castellano servía para afirmar los nuevos valores políticos y económicos de la burguesía y de labradores prósperos, y, a veces, hasta para resistir la violencia y el ejercicio inmoderado del poder por la nobleza.

\section{LA CONSOLIDACIÓN DE LA PROPIEDAD}

Hay otro aspecto histórico de los límites de propiedad que merece mención como un ejemplo más de la forma en que los castellanos comenzaron a conceptualizar la propiedad a finales del siglo XII y principios del XIII. En esa época, muchos de los documentos que describen transacciones de tierra comienzan a incluir, en mayor cantidad y con mayor precisión que en épocas anteriores, descripciones elaboradas de las tierras limítrofes o de los accidentes geográficos que servían de límites a la propiedad recién adquirida. Aunque todavía en los siglos XIV y XV muchos de los documentos que registran transacciones de tierra carecen todavía de gran precisión en los detalles de la extensión actual de la propiedad, en ciertas regiones de la Castilla septentrional la documentación muestra un cuidado especial en

\footnotetext{
2) Véase Libro Becerro de las Behetrias. Estudio y texto crítico, G. Martínez Dízz. ed. (3 vols. León. 1981), II. pp. 175-182 et passim.
} 
indicar cuáles eran los terrenos circundantes, a quiénes pertenecían, qué camino o río, o propiedad comunal servía como término de la propiedad.

Este tipo de documentación aparece con más frecuencia en regiones con cierta densidad de población e intensa labor agrícola. Éste es el caso en las numerosas compras de tierras efectuadas por el monasterio de las Huelgas en una serie de aldeas de la región de Dueñas, entre los años 1229 y 1267. Durante estos 33 años, las monjas de Las Huelgas participaron al menos en 53 compras (éste es el número de transacciones que se conservan), aunque el número actual, como se deduce de la documentación que poseemos, debió de ser mucho mayor.

La elaborada descripción de las tierras limítrofes que encontramos en esta serie de documentos refleja, en parte, el deseo del monasterio de definir con gran precisión cuánta tierra poseía y dónde. Estas transacciones, junto con cientos de otros documentos similares, nos revelan un cambio dramático en la manera de pensar acerca de la tierra, en el deseo y forma de adquirir propiedades y en imaginarla espacialmente. En un reciente libro ya he examinado como en casi todo el norte de Castilla, concejos municipales, monasterios, miembros de las élites urbanas llevaron a cabo un agresivo plan de adquisición de tierras en el campo castellano. Las tierras de aldeas situadas en las inmediaciones de importantes villas y ciudades, tales como Burgos, Segovia, Ávila, Dueñas, Soria y otras, fueron monopolizadas por unos pocos ricos burgueses, por instituciones religiosas y municipios y fueron transformados desde su heterogéneo y fragmentado estado inicial en grandes fincas donde la propiedad se había consolidado dentro de unos límites específicos. En el pasado, al examinar estos datos, mi interés se limitó a emplear este tipo de transacciones como un ejemplo más de la intrusión del capital urbano en tierras de las comarcas adyacentes a la ciudad; pero, en realidad, la evidencia también nos muestra una fuerte tendencia a consolidar la propiedad, o sea, a comprar tierras que estuviesen contiguas a las que uno ya poseía. Este hecho, en sí, ya es señal de una transformación en la manera de percibir la propiedad: de propiedad como derechos y rentas fragmentados y esparcidos a través de toda una región (como es el caso de los derechos descritos en el Becerro de Behetrías) a la tierra como propiedad, como espacio físico indiviso ${ }^{21}$. Existía también,

\footnotetext{
${ }^{21}$ Teófilo F. Ruiz, Crisis and Continuity. Land and Town in Late Medieval Castile, Philadelphia, 1994, capítulos 4, 5 y 8.
} 
claro está, la creciente realidad de que trabajar un terreno específico, por lo general con jornaleros, era más rentable; pero la realización de esta idea es ya parte de los cambios en el sistema de valores del mundo castellano que intento describir ${ }^{22}$.

La tendencia a consolidar la propiedad puede ser situada en el período crítico de finales del siglo XII y comienzos del XIII, aunque hay ejemplos aislados de este tipo de transacciones en una época anterior ${ }^{23}$. Ello coincidió con la transformación de la estructura económica del reino y la ascendencia comercial de ciertas ciudades del norte de Castilla como centros de distribución del comercio internacional. El aumento en la circulación de monedas, el cambio en la dirección del comercio castellano, del al-Andalús al norte de Europa y los inicios de la comercialización de la agricultura (cereales de la Tierra de Campos, vino de la Rioja, etc.) son quizás algunas de las causas que explican las nuevas formas de pensar acerca de, ya no sólo la propiedad, sino otras categorías sociales y culturales como la salvación, la caridad y la representación de uno mismo.

Mi más reciente libro, Crisis and Continuity, como ya indiqué anteriormente, contiene abundantes pruebas de esta tendencia a consolidar propiedades y a la concentración de la propiedad en una sola o en unas cuantas grandes haciendas, lo que más tarde serían mayorazgos. Pero esto ocurrió ya no sólo entre la gente poderosa, sino aún también - aunque a una escala mucho menor- entre campesinos hacendados (para utilizar la designación ya empleada por Moxó). O sea, que el fenómeno de concentración de tierras en las manos de unos pocos fue replicado al nivel de la aldea. En muchos sentidos, este tipo de transformación señaló una amenaza al sistema comunitario de las aldeas del norte de Castilla. Por un lado, la consolidación de la tierra a varios niveles, así como la destrucción de la aldea comunitaria, fueron subvertidos, modificados en parte $y$, aun a veces, derrotados por la práctica, bien difundida en el mundo rural castellano, de dividir los bienes en partes iguales al momento de la muerte y también por las costumbres ancestrales de la aldea que favorecían formas tradicionales de

\footnotetext{
${ }^{22} \mathrm{El}$ cambio de un sistema de valores en la Castilla septentrional en los siglos XII y XIII es el tema que trata un libro, en el que estoy trabajando actualmente, que será publicado por la Princeton University Press con un título que será aproximadamente así: From Heaven to Earth: Property, Salvation, Language and Representation in Late Medieval Castile.

${ }^{23}$ Véase María del Carmen CARLÉ, Gran propiedad y grandes propietarios, "Cuadernos de Historia de España", 57-58 (Buenos Aires 1976), pp. 1-224.
} 
organizar el espacio agrícola. Este conflicto entre privatización y tradición comunal es la coyuntura mas importante en la historia rural de Castilla. Un continuo ir y venir de tendencias contrarias, donde formas tradicionales de un pasado lejano coexistían con las transformaciones del presente ${ }^{24}$.

\section{DERECHOS DE ENTRADA Y SALIDA}

Nuestra última prueba en este artículo proviene de las numerosas compra-ventas y cambios de tierras de finales del siglo XII y principios del XIII. Desde una época anterior, las transacciones y donaciones de tierras incluían formulas tradicionales tales como "...illa hereditate in loco qui dicitur Villota et Villateca, et Sancti Stephani, cum suas hereritates et divisa, in montes, in fontes, in pratis, cum exitus et introitus" ${ }^{25}$. Las transacciones de tierra redactadas en castellano continúan empleando expresiones similares "con entrada y con salida" hasta finales del medioevo. El derecho a entrar y salir de la tierra propia era ya parte del paisaje mental de los castellanos desde el comienzo de la región como una realidad política en el siglo IX. La transformación que tiene lugar a finales del siglo XII y comienzos del XIII fue, como ocurrió con la definición de límites y la consolidación de la propiedad, un cambio cualitativo y de formas de imaginar la propiedad. La evidencia más apropiada para estos cambios la encontramos en el excelente y pionero estudio de Luis Martínez García, La concentración de la propiedad urbana burgalesa mediante la concesión de "pasadas de tierra" (1150-1250). En este artículo, Martínez García realiza un examen concienzudo de 291 cambios y compra-ventas de "pasadas de tierra" con derechos de entrada y salida. Este tipo de transacción que, en cierto modo, es bastante peculiar de la región de Burgos, nos muestra una preocupación extrema por el derecho de poder acceder a la propiedad de uno mismo sin obligaciones hacia los propietarios de las tierras o casas circundantes.

Martínez García estudia, en particular, estas compra-ventas para ilustrar cómo la oligarquía de Burgos consolidó sus propiedades en el ámbito urbano; pero, como él mismo indica, las transacciones fueron esencialmente

\footnotetext{
${ }^{24}$ Sobre este tema, véase David VASSBERG, Land and Society in Golden Age Castile, Cambridge, Inglaterra, 1984; Ruth BEHAR, Santa Maria del Monte: The Presence of the Past in a Spanish Village, Princeton, 1986.

${ }^{25}$ Cartulario de San Millán de la Cogolla (759-1076), pp. 27, 28 et passim.
} 
la concesión de un derecho de pasar a través de la propiedad de otra persona y de ganar acceso a una vía o espacio público ${ }^{26}$. Por ejemplo, en agosto de 1202, Guillermo Gascón, su mujer Estefanía y su hijo Ordonio, cambiaron la propiedad que ellos tenían en Quintanilla Muniocisla por "unam passatam terre, in longo et in amplo, cum introitu et exitu, ante domum uestram qua habetis in Quintanilla et de super XI morabetinos alfonsi..." ${ }^{27}$. La documentación estudiada por Martínez García, debemos reiterar, concierne, esencialmente, el mundo urbano de Burgos - aunque esta última cita, sin embargo, se localizaba en una pequeña aldea en el alfoz de la ciudad-y se limitan, por lo general, a cambios o compra-ventas de propiedades, derechos de molienda y dinero a cambio de "una passatam terra, cum intrada et exida" intramuros ${ }^{28}$.

Para resumir el argumento previo, los documentos de Burgos nos muestran un buen número de transacciones de tierra por derechos de entrada y salida, o sea, para crear un paso o vía a través de la propiedad de otra persona, que diese acceso a una vía publica. Aparte de intentar poner orden en el caótico desarrollo urbano de Burgos y de otras ciudades castellanas, estas transacciones por "passatam de terra" -que en sí garantizaban derechos de entrada y salida - nos informan sobre maneras de percibir la propiedad en términos de espacio y de acceso a una vía pública. El derecho de pasaje es una de las características indudables del mundo moderno. ¿Es qué las transacciones por pasadas de tierra representan un cambio paradigmático en la mentalidad castellana? ¿Es qué estos cambios y compra-ventas nos indican la génesis de una nueva conciencia de la relación entre derechos de paso, límites territoriales, libertad de movimiento y poder político y económico? Es mi opinión que la desaparición de este tipo de transacciones después de la década de 1220 señala el paso a un mundo en el que una propiedad, ya sea urbana o rural, sin acceso a una vía pública, a una calle, era inconcebible, y que la propiedad, todas las propiedades, no tenían uso práctico sin el derecho de entrada y salida. Es más, aunque la fórmula

\footnotetext{
${ }^{26}$ Luis MARTÍNEZ GARCIA, La concentración de la propiedad urbana burgalesa mediante la concesión de "pasadas de tierra" (1150-1250), en "La ciudad de Burgos", León, 1985, pp. $89-90$.

${ }^{27}$ Documentación de la catedral de Burgos (1184-1222), ed. J.M. GARRIDo GARRIDO, en "Fuentes Medievales Castellano-Leonesas" ("FMCL"), 14 (Burgos, 1983), pp. 152-153 et passim.

${ }^{28}$ Véase otro ejemplo en el Archivo de la Catedral de Burgos, vol. 70, no 170 (i-7-1212), publicado en Documentación de la catedral de Burgos, cit, p. 254.
} 
"vendo tal y cual propiedad con los derechos de entrada y salida" continúa en uso en los documentos de épocas posteriores a 1220, un buen número de transacciones de tierra cesan de incorporar un lenguaje que se había convertido, ya en una época posterior, en un mero formalismo. Ya en las postrimerías de la Edad Media resultaba evidente que la tierra no podía ser vendida, comprada o transferida sin incluir el derecho de entrada y salida, y una gran parte de la documentación comienza a incorporar descripciones detalladas de los límites de la tierra en cuestión. En sí, estos límites, explicitamente, yá mostraban el acceso a un camino público ${ }^{29}$.

\section{CONCLUSION}

A finales del siglo XII y comienzos del XIII, las transformaciones en la mentalidad de ciertos grupos sociales en Castilla -implícito en el tránsito de un sentido jurisdiccional de la tierra a uno de la tierra como espacio geográfico, así como en el creciente número de mojones que funcionaban como símbolos de límites locales de la tierra y como partes de un imaginario de "liminalidad" - sirvieron como fundamento indispensable para la génesis de límites regionales y, en una época posterior, para los límites territoriales del reino y de la nación. Los reyes de Castilla, en su frenética construcción de aduanas y fortificaciones de frontera en el siglo $\mathrm{XV}$, sólo seguían el ejemplo que habían aprendido de las comunidades locales. Tomando prestados los aspectos prácticos de cómo definir un territorio espacialmente, ya empleados en el siglo XIII por campesinos y comunidades rurales, los reyes de Castilla y sus agentes formularon nuevos conceptos de soberanía, una idea implícita en la creación de fronteras nacionales.

\section{RÉSUMÉ}

Dans mon article Frontières: De la communaute à la nation dans la Castille de la fin du Moyen Age, je montre que l'émergence des concepts de souveraineté, de frontières nationales et d'un "espace national" en Castille à la fin du Moyen Âge et au début des

\footnotetext{
${ }^{29}$ Véase Documentación del monasterio de la Trinidad de Burgos (1198-1400), ed. L. García ARAGÓN, "FMCL", 28 (Burgos, 1985), pp. 191-192 (1368); pp. 225-226 (1373); 246247 (1378) et passim.
} 
Tempes Modernes est liée, entre autres dévelopments théoriques et politiques, à l'apparition des limites territoriales et à l'organisation de l'espace physique au niveau des communautes locales entre la fin du XII et le début du XIII' siècle. Les limites nationales, l'idée du royaume comme concept spatial, n'auraient pu être articulées ou imaginées sans cet enracinement antèrieur dans les expèriences locales. Ainsi, cet article étudie essentiellement le passage d'une definition de la propriété comme jurisdiction seigneuriale et rentes à celle d'un aménagement spatial du territoire dans les villages de la Castille septentrionale. Trois types de sources sont passés en revue: 1) celles qui mettent en évidence la délimitation de l'espace géographique au moyen de bornes artificielles (mojones); 2) les documents qui analysent la consolidation de la propriété dans des domains contigus; 3) les transactions foncières qui dévoilent la preoccupation croissante pour les droits d'entrée et de sortie.

\section{SUMMARY}

In my article, Borders: From Community to Nation in Late Medieval Castile, I argue that the development of concepts of sovereignty, national frontiers and a "national" space in late medieval and early modern Castile was linked, among other theoretical and political developments, to the emergence of territorial boundaries and the ordering of physical space at the level of local communities in the late twelfth and early thirteenth centuries. National boundaries, the idea of the realm as a spatial concept, could not have been articulated or imagined without a previous grounding in local experiences. Thus, the main portions of the article explore the transition from definitions of property as seignorial jurisdiction and rents to a spatial ordering of the land in villages throughout northern Castile. Three types of evidence are examined: 1) sources which describe the limiting of geographical space by the use of artificial landmarks (mojones); 2) those documents which describe the consolidation of property into contiguous estates; 3 ) transactions of land which show an increased preoccupation with rights of "entry and exit". 